\title{
Detección y tipificación de virus papiloma humano en lesiones preneoplásicas del cuello uterino mediante PCR-RFLP
}

\author{
Susana Aedo A ${ }^{1}$, Angélica Melo A ${ }^{1}$, Patricia G arcía ${ }^{1}$, \\ Pablo Guzmán $\mathrm{G}^{1}$, Italo Capurro $\mathrm{V}^{2}$, Juan Carlos Roa $\mathrm{S}^{1}$. \\ Detection and typification of human \\ papilloma virus \\ in pre cancerous cervical lesions
}

Background: The association of different genotypes of human papilloma virus (HPV) with cervical cancer is well known. However, there is little information about their association with pre-cancerous lesions. Aim: To assess the frequency of different HPV genotypes in pre cancerous cervical lesions. Material and methods: A cervical sample was obtained by cytobrush in 15 women with low grade lesions and 40 women with high grade lesions, subjected to conization by loop electrical excision procedure (LEEP). Detection and typification of HPV was done by polymerase chain reaction and restriction fragment length polymorphism. Results: All women were infected with HPV. Eighty five percent of samples were typified. A unique HPV subtype was found in $76 \%$ of women. Fourteen percent had an infection with multiple subtypes and in $10 \%$, the viral genotype was not identified. The most common subtypes found were HPV 16, HPV 52 and HPV 53. Conclusions: There is a high rate of infection with HPV with a high oncogenic risk among these women (Rev Méd Chile 2007; 135: 167-73). (Key words: Human papilloma virus; Oncogenes; Uterine cervical cancer)

Recibido el 7 de marzo, 2006. Aceptado el 16 de agosto, 2006.

Financiado en parte por la Dirección de investigación de la Universidad de La Frontera. Parcialmente financiado por proyecto DIUFRO 120534.

Tesis de licenciatura de TM Susana Aedo.

${ }_{1}^{1}$ Departamento de Anatomía Patológica, Facultad de Medicina, Universidad de La Frontera. Temuco, Chile. ${ }^{2}$ Departamento de Obstetricia y Ginecología, Facultad de Medicina, Universidad de La Frontera. Temuco, Chile.

Correspondencia a: Dr. Juan Carlos Roa. Departamento de Patología, Facultad de Medicina, Universidad de La Frontera. Manuel Montt 112. Temuco, Chile. Código Postal 478-1176.

E mail: jcroa@ufro.cl 
$E^{\mathrm{n}}$ Chile, el cáncer de cuello uterino (CCU) ocupa el tercer lugar entre los cánceres de la mujer, después del cáncer de vesícula biliar y el cáncer gástrico. En la IX región, el CCU corresponde a $11,7 \%$ del total de tumores malignos, ocupando el segundo lugar en las mujeres con 20,3\%1.

La infección genital por virus papiloma humano (HPV) es una enfermedad de transmisión sexual2,3 con una reconocida asociación con lesiones preneoplásicas y neoplásicas del cuello uterino ${ }^{4-6}$. En nuestro país, existen escasos estudios publicados sobre detección de HPV y su relación con neoplasia cervical intraepitelial (NCI) y CCU ${ }^{7,8}$. Los genotipos de HPV que infectan el tracto genital femenino, se han clasificado en 2 grupos: de bajo riesgo (BR) y de alto riesgo (AR) según el potencial oncogénico para el desarrollo de lesiones preneoplásicas o neoplásicas. Los genotipos de bajo riesgo (BR) más frecuentes son los HPV: 6, 11, 43 y 44 y se asocian con condilomas o neoplasias cervicales intraepiteliales de bajo grado (LBG). En el grupo de alto riesgo (AR) 15 tipos de HPV han sido identificados (HPV 16, 18, $31,33,35,39,45,51,52,56,58,59,68,73$ у 82), detectados principalmente en neoplasia cervical intraepitelial de alto grado (LAG) y carcinomas ${ }^{9-11}$.

Uno de los métodos más usados para la detección de HPV en muestras de citología cervicouterina es la captura híbrida, que cuenta con la aprobación de la Food and Drug Administration (FDA) para uso clínico ${ }^{12,13}$ y se utiliza como método de screening ${ }^{14}$. Sin embargo, esta técnica discrimina solamente entre tipos de AR y BR, sin informar sobre el genotipo viral específico. La reacción en cadena de la polimerasa (PCR) es, actualmente, el método más sensible para la detección de HPV. Se han desarrollado diferentes protocolos de PCR para detectar un amplio espectro de genotipos de HPV, usando partidores genéricos que reconocen secuencias específicas del genoma viral ${ }^{15-18}$. Para tipificar los tipos virales a partir de los productos de la amplificación, se han utilizado distintos métodos: Southern blot, hibridación Dot Blot, enzimas de restricción (RFLP), secuenciación y enzimoinmunoensayo ${ }^{19,20}$.

En nuestro país, dos estudios realizados en muestras citológicas en mujeres aparentemente sanas, utilizando el método de «captura híbrida» y enzimoinmunoensayo detectaron ADN HPV en $8 \%$ y $14 \%$ de las pacientes. En estos estudios $83,8 \%$ y $71 \%$ de los casos, respectivamente, correspondió a HPV $\mathrm{AR}^{21,22}$, sin embargo, no existe mayor información en portadoras de lesiones preneoplásicas.

El objetivo de este estudio fue determinar la frecuencia de los distintos genotipos de HPV cervical en muestras de cepillado cervical en un grupo de mujeres con diagnóstico de LBG y LAG cervical uterina, mediante técnica combinada de PCR-RFLP.

\section{MATERIAL Y MÉTODO}

Muestra. Se analizaron muestras de cepillado cervical de un total de 55 mujeres del policlínico de Patología Cervical del Hospital Hemán Henńquez Aravena de Temuco, con diagnóstico histopatológico de: LBG (displasia leve y signos morfológicos de infección por virus papiloma) y LAG (displasia moderada, displasia intensa, carcinomas in situ). La muestra se recolectó momentos antes de la realización de una conización mediante asa LEEP (loop electrical excision procedure). El estudio fue autorizado por el Comité de Ética del Servicio de Salud de la Región de la Araucanía y las pacientes fueron ingresadas previa firma de consentimiento informado.

El material cervical se recolectó en $3 \mathrm{ml}$ de Buffer TE pH 7.4 (10 mM Tris.Cl, 1 mM EDTA pH 8). El ADN fue extraído con el kit Puregene ${ }^{T M}$ DNA Isolation System (Gentra System, USA) siguiendo las instrucciones del fabricante. El ADN se almacenó a $-20^{\circ} \mathrm{C}$ hasta su análisis. Se certificó la calidad del ADN extraído, mediante la amplificación fragmento de 268 pares de bases (pb) dentro del gen $ß$-globina, usado como un control interno, con los iniciadores PCO 4 5' CAA CTT CAT CCA CGT TCA CC 3' y GH20 5' GAA GAG CCA AGG ACA GGT AC $3^{123}$.

Detección de HPV. La detección de HPV se realizó mediante PCR anidada (PCR L1), usando el par de iniciadores de consenso externos MY09/MY114 y el par de iniciadores internos $\mathrm{GP} 5+/ \mathrm{GP} 6+^{4}$, dirigidos a la región L1 del HPV y que amplifican un fragmento de 450 y $150 \mathrm{pb}$, respectivamente. Se utilizaron como controles positivos plásmidos recombinantes para los tipos de HPV: 6, 16 y 18. Como control blanco se reemplazó el ADN por agua desionizada. El análisis de los productos de amplificación se realizó mediante electroforesis en gel de agarosa al $2 \%$ teñido con bromuro de etidio. 
Tipificación de subtipos virales mediante PCRRFLP. Se utilizó primers My09/My11 que amplifican fragmento de $450 \mathrm{bp}$. El producto PCR fue sometido a RFLP con las enzimas Rsa I y Dde I, cuyas secuencias específicas de corte son GT/AC y C/TNAG, respectivamente. Donde $\ll$ N»indica que en esa posición puede situarse cualquiera de las 4 bases. Se incubaron durante $14 \mathrm{~h}$ a $37^{\circ} \mathrm{C}$. Los fragmentos digeridos fueron sometidos a electroforesis en geles de poliacrilamida al $10 \%$.

Para interpretar el polimorfismo de los fragmentos digeridos, se confeccionó un patrón de restricción para cada enzima. Las secuencias completas de los tipos más frecuentes de HPV (AR y BR) se obtuvieron del GeneBank (www.ncbi.nlm.nih.gov/ taxonomy). Se ubicó la región L1, y dentro de ésta, la posición de los iniciadores y los puntos de corte de cada enzima.

En la Figura 1 se presenta el patrón de restricción con la enzima Rsa I. En los carriles 1 y 5 corresponde al tipo HPV 18, en el carril 4 al HPV 35. En los carriles 2 y 3, los fragmentos de restricción son del mismo tamaño para los tipos HPV 16 y 56; esto se resuelve utilizando una segunda enzima (DdE I), que divide nuevamente los fragmentos amplificados en tamaños únicos y específicos para los genotipos HPV16 56.

\section{Resultados}

Del total de los 55 casos estudiados, 15 correspondieron a lesiones de bajo grado, 40 a lesiones de alto grado; la edad de los pacientes fluctuó entre 18 y 77 años, con un promedio de 38,5 años. Detección de HPV: Dos fueron ß-globina negativas y, por tanto excluidas del estudio. De las 53 muestras restantes, todas resultaron HPV positivas con la PCR L1 anidada (fragmento de 150pb). Sin embargo, cuando se realizó la PCR simple L1 outer, se obtuvo suficiente producto de PCR (450 $\mathrm{pb})$ requerido para las digestiones enzimáticas (RFLP) en 48 de los 53 casos (90,6\%).

Tipificación de HPV. Los resultados de la tipificación viral se observan en la Tabla 1. Se detectaron 13 genotipos diferentes de HPV, el más frecuente fue el HPV 16, con 30,8\%, seguido por el HPV 52,

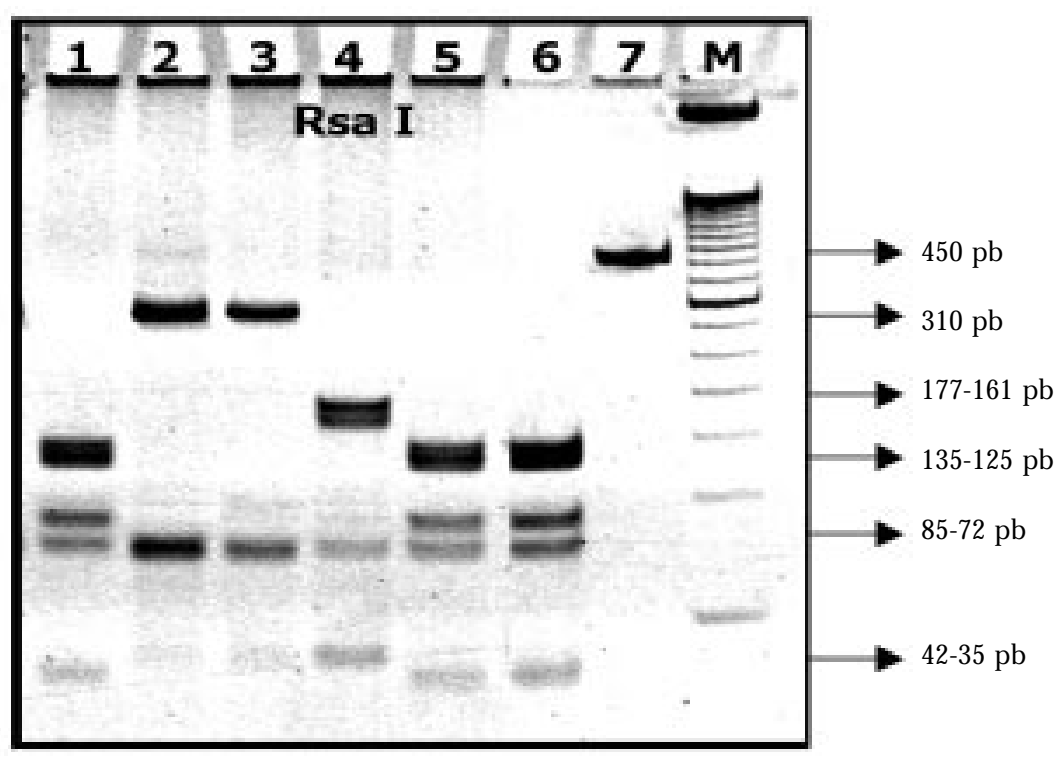

Figura 1. Digestión con la enzima Rsa I de muestras CB HPV positivas. Gel de poliacrilamida al $12 \%$ teñido con bromuro de etidio. M: marcador 50 pb, Carril 1 y 5: HPV 18 (135, 125, 85, 72 y 38 pb) Carril 2 y 3: HPV 16 ó 56 (310, 72 y 70 pb), Carril 4: HPV 35 (177, 161, 72 y 42 pb), Carril 6: Plásmido HPV 18 Blanco (135, 125, 85, 72 y 38 pb). Carril 7: pPCR usado como control, sin digestión enzimática (450pb). 
Tabla 1. Tipificación de los casos H PV positivos según clasificación histológica

\begin{tabular}{|c|c|c|c|c|c|c|c|c|c|c|c|c|c|c|}
\hline \multirow{2}{*}{$\begin{array}{l}\text { Clasificación } \\
\text { histológica }\end{array}$} & \multicolumn{14}{|c|}{ Genotipos de HPV (n/\%) } \\
\hline & $\mathrm{n}$ & 11 & 16 & 18 & 31 & 33 & 35 & 39 & 42 & 52 & 53 & 56 & 58 & 59 \\
\hline LBG & 8 & 0 & $1 / 12,5$ & 0 & $1 / 12,5$ & 0 & 0 & $1 / 12,5$ & 0 & $3 / 37,5$ & $1 / 12,5$ & 0 & 0 & $1 / 12,5$ \\
\hline LAG & 44 & $1 / 2,3$ & $15 / 34,1$ & $6 / 13,6$ & $1 / 2,3$ & $2 / 4,5$ & $1 / 2,3$ & $2 / 4,5$ & $1 / 2,3$ & $4 / 9,1$ & $5 / 11,4$ & $1 / 2,3$ & $1 / 2,3$ & $4 / 9,1$ \\
\hline Total & 52 & $1 / 1,9$ & $16 / 30,8$ & $6 / 11,5$ & $2 / 3,8$ & $2 / 3,8$ & $1 / 1,9$ & $3 / 5,8$ & $1 / 1,9$ & $7 / 13,5$ & $6 / 11,5$ & $1 / 1,9$ & $1 / 1,9$ & $5 / 9,6$ \\
\hline
\end{tabular}

Los genotipos de HPV tabulados corresponden tanto a casos con infección única o múltiple.

LBG: neoplasia cervical intraepitelial de bajo grado. LAG: neoplasia cervical intraepitelial de alto grado.

con 13,5\%, el HPV 18 y 53, con 11,5\%, el HPV 59, con $9,6 \%$ y HPV 31, con 3,8\%. Los genotipos menos frecuentes fueron el HPV 11, 35, 42, 56 y 58 , con un $1,9 \%$. Se destaca en esta Tabla que el genotipo HPV 16 fue el más frecuente en las LAG $(34,1 \%)$ y el subtipo HPV 52 (37,5\%) en las LBG. En 15\% (7/48) de los casos se logró identificar casos que presentaban infección múltiple (IM) (Tabla 2).

\section{Discusión}

Las frecuencias observadas para el HPV 16 y 18 son similares a lo reportado en estudios previos realizados en la región ${ }^{7,8}$ y el alto número de HPV de AR es comparable a la prevalencia de casos de CCU que presenta nuestra región ${ }^{1}$. Los virus de AR HPV 16, 18, 52, 53, fueron los más frecuentemente encontrados, tanto en las LBG como en las LAG. En el presente estudio, el HPV 16 fue el genotipo más frecuente, coincidiendo con lo descrito en México ${ }^{24}$ y otros países latinoamerica- nos $^{25-28}$. Otros subtipos virales como HPV 18, HPV 45, HPV 31 y HPV 33 han sido encontrados los más frecuentes en diversas series ${ }^{7,29-31}$. En nuestro estudio, se observó como el genotipo de mayor frecuencia es HPV 52 en las LBG $(37,5 \%)$ y el HPV $16(34,5 \%)$ en las LAG seguido por el HPV 18. No obstante, es un hecho conocido la existencia de diferencias geográficas en cuanto a la frecuencia de los HPVs. Liaw y cols, fueron los primeros en reportar que los HPV 52 y 58 eran los subtipos más prevalentes en LAG y carcinoma en China $^{32}$. En Asia, los HPV 58 y 52 son más comunes que HPV 43, 31 y $33^{31}$ Bayo y cols, en Mali, Africa, describió a HPV 51 y 73 en biopsias frescas de carcinoma como nuevos genotipos frecuentes de HPV, aparte del HPV 16 y $18^{31}$. Sasagawa y cols, observaron los genotipos de HPV 11, 39, 42, 44, 53, 54 y 59 exclusivamente en LBG y no encontraron los tipos 39, 53 y 59 que son considerados de AR en LAG y carcinoma invasor ${ }^{33}$.

La técnica de PCR-RFLP tiene la característica de poder determinar más de 30 genotipos virales

Tabla 2. Frecuencia de subtipos en infecciones múltiples según clasificación histológica

\begin{tabular}{|lcccccccc|}
\hline Clasificación & \multicolumn{7}{c|}{ Infección } & \multicolumn{8}{c|}{ múltipple $($ genotipos asociados) } \\
& $\mathrm{n}$ & $18 / 59$ & $18 / 53$ & $31 / 52$ & $31 / 53$ & $18 / 42$ & $39 / 52 / 59$ & $11 / 18 / 59$ \\
\hline LBG & 1 & 0 & 0 & 0 & 1 & 0 & 0 & 0 \\
LAG & 6 & 1 & 1 & 1 & 0 & 1 & 1 & 1 \\
Total & 7 & 1 & 1 & 1 & 1 & 1 & 1 & 1 \\
\hline
\end{tabular}

LBG: neoplasia cervical intraepitelial de bajo grado. LAG: neoplasia cervical intraepitelial de alto grado. 
anogenitales con una única reacción de amplificación, siendo su mayor ventaja frente a las metodologías que emplean iniciadores específicos, pero su mayor desventaja es justamente no poder definir en ciertos casos los genotipos asociados cuando se presentan infecciones múltiples, que frecuentemente producen patrones de restricción confusos. Frente a estos resultados, se puede optar por otras metodologías moleculares de identificación como son la PCR con posterior hibridación por Dot Blot, PCR con iniciadores específicos, o la secuenciación, permitiendo verificar variantes dentro de un subtipo o nuevos genotipos de $\mathrm{HPV}^{34-36}$. En nuestro estudio, 5 (10\%) muestras presentaron patrones de restricción que no coincidieron con los tipos de HPV incluidos en la Tabla 1. Este hecho es esperable, ya que sólo se trabajó con 2 enzimas.

En 15\% (7/48) de los casos se logró, con las 2 enzimas de restricción empleadas, identificar casos que presentaban IM y los subtipos involucrados. El HPV 18 fue el más frecuente, seguido por el HPV 59. En dos casos fueron identificables 3 genotipos virales. Los genotipos HPV 11 y HPV 42 (considerados de BR) y el HPV 31 solamente se observaron en casos con IM (Tabla 2).

La IM ha sido mencionada como un factor común en mujeres jóvenes y se explica por resistencia inmunológica, permitiendo que una infección por HPV persista ${ }^{37}$, provocando además, mayor susceptibilidad a una reinfección ${ }^{37,38}$. Por otro lado, se ha reportado que en los casos con IM, no ha habido un aumento significativo en el riesgo de desarrollar una NCI al compararlos con mujeres infectadas con un solo genotipo viral ${ }^{39}$.

Cinco muestras de HPV positivas no pudieron someterse a restricción enzimática debido a la

\section{REFERENCIAS}

1. Serra i SL, Castro R, García V, Serra J, Desinti E, CÁrcamo S. Cáncer cervicouterino, un desafío sin resolver. Rev Chil Obstet Ginecol 1997; 62: 75-85.

2. Ponten J, Guo Z. Precancer of the human cervix. Cancer Surv 1998; 32: 201-29. escasa cantidad de material amplificado, insuficiente para generar un patrón de bandas analizable. Suponemos que estos casos pueden corresponder a aquellos en los que la carga viral en la muestra obtenida se encuentra en el límite de la sensibilidad de la técnica. Estudios publicados han concluido que el uso de una PCR anidada, usando los iniciadores MY09/MY11 y GP5+/GP6+, puede aumentar considerablemente su sensibilidad de 10 a 100 veces, en comparación con una PCR simple que emplea únicamente los iniciadores MY09/MY1140-42. Un estudio multicéntrico realizado en España y Colombia, utilizó los iniciadores MY09/MY11 e identificó ADN viral en $75 \%$ de los casos; el resto de las muestras las reanalizaron usando el sistema GP5+/GP6+ y obtuvieron un incremento de $20 \%$ en el rango de detección del ADN viral ${ }^{39}$.

Finalmente, podemos decir que la utilización de la técnica de PCR-RFLP para la detección de HPV en muestras de cepillado cervical fue exitoso y que permitió identificar en nuestros pacientes los genotipos virales considerados epidemiológicamente más importantes. Por otro lado, los resultados del presente estudio demuestran que, además del HPV 16 que es el de mayor prevalencia a nivel mundial, se debe prestar atención a otros genotipos, que aunque de menor frecuencia pudieran tener importancia epidemiológica local.

La alta frecuencia de HPV de alto riesgo oncogénico, en lesiones de alto y bajo grado surge como buena explicación para las altas incidencias de cáncer cervicouterino en nuestra región. Conocer la frecuencia y distribución de los subtipos virales de HPV puede contribuir a medir la efectividad de una eventual vacuna en nuestra población y ayudar a racionalizar los recursos de nuestro programa nacional de detección de cáncer cuello uterino. 
virus in cervical cancer: a perspective. International biological study on cervical cancer Study Group. J Natl Cancer Inst 1995; 87: 796-802.

5. Munoz N, Bosch FX. The causal link between HPV and cervical cancer and its prevention of cervical cancer. Bull Pan Am Health Organ 1996; 30: 362-77.

6. VIшA LL, FRANCO EL Epidemiologic correlates of cervical neoplasia and risk of human papilloma virus infection in asymptomatic women in Brazil. J Natl Cancer Inst 1989; 81: 332-40.

7. Melo A, Montenegro S, Hooper T, Capurro I, Roa JC, RoA I. [Human papilloma virus (HPV) typing in preneoplastic and lesions of the uterine cervix in the IX region-Chile]. Rev Méd Chile 2003; 131: 1382-90.

8. Melo A, Montenegro S, Roa I, Capurro i, Roa JC. Estudio comparativo de detección del virus papiloma humano (HPV) en muestras citológicas y biopsias de cuello uterino. Rev Méd Chile 2005; 133: 639-44.

9. Munoz N, Bosch FX, de Sanjose S, Herrero R, Castellague $\mathrm{X}$, Shah KV et al. Epidemiologic classification of human papilloma virus types cervical cancer. N Engl J Med 2003; 348: 518-27.

10. VIшA LL Human papilloma viruses and cervical cancer. Adv Cancer Res 1997; 71: 321-41.

11. Sasagana T, Dong Y, Saijoh K, Satake S, Tateno M, Inoue M. Human papilloma virus infection and risk determinants for intraepithelial lesion and cervical cancer in Japan. Jpn J Cancer Res 1997; 88: 376-84.

12. JeNKINS D. Diagnosing human papilloma viruses: recent advances. Curr Opin Infect Dis 2001; 14: 53-62.

13. Ronco G. [Use of molecular tests of human papilloma virus (HPV) as for cervix cancer: a review]. Epidemiol Prev 1999; 23: 372-7.

14. LoRINCZ AT, RichaRT RM. Human papilloma virus DNA testing as an adjunct to cytology in cervical screening programs. Arch Pathol Lab Med 2003; 127: 959-68.

15. Manos MM TY, Wright DK, Lewis A, Broker T, WoLnssKY $S$. Use of polymerase chain reaction amplification for the detection of genital human papilloma viruses. Cancer Cells 1989; 7: 209-14.

16. Fujinaga $Y$, Shimada M, Okazawa K, Fukushima $M$, Kato I, Fujinaga K. Simultaneous detection and typing of genital human using the polymerase chain reaction. J Gen Virol 1991; 72: 1039-44.
17. Snijders PJ, van den Brule AJ, Schrijnemakers HF, Snow G, MejJer CJ, Walboomers JM. The use of general primers in the polymerase chain reaction detection of a broad spectrum of human papilloma virus genotypes. J Gen Virol 1990; 71: 173-81.

18. de Roda Husman AM, Walboomers JM, van den Brule AJ, Mejer CJ, SNijders PJ. The use of general primers GP5 and GP6 elongated at their 3' adjacent highly conserved sequences improves human detection by PCR. J Gen Virol 1995; 76: 1057-62.

19. RESNick RM, CoRNeLISSEN MT, WRight DK, EICHINGER GH, Fox HS, ter Schegget J et al. Detection and typing of human papilloma virus in archival specimens by DNA amplification with consensus primers. J Natl Cancer Inst 1990; 82: 1477-84.

20. Jacobs MV, de Roda Husman AM, van den Brule AJ, Snijders PJ, Meijer CJ, Walboomers JM. Groupspecific differentiation between high- and lowrisk human papillomavirus genotypes by general primer-mediated PCR and two of oligonucleotide probes. J Clin Microbiol 1995; 33: 901-5.

21. Socias M GJ, Figueroa J, Fernández F. Perfil epidemiológico y clínico de la tipificación del HPV captura híbrida, método DIGENE. Rev Chil Obstet Ginecol 1997; 62: 167-73.

22. Ferreccio C, Prado RB, Luzoro AV, Ampuero SL, SNIJDERS PJ, MeIJER CJ ET AL. Population-based prevalence and age distribution of human papilloma virus among women in Santiago, Chile. Cancer Epidemiol Biomarkers Prev 2004; 13: 2271-6.

23. Giulano AR, Papenfuss $M$, Abrahamsen M, Denman $C$, de ZAPIEN JG, HeNZe JL et al. Human papilloma virus infection at the United States-Mexico implications for cervical cancer prevention and control. Cancer Epidemiol Biomarkers Prev 2001; 10: 1129-36.

24. Lazcano-Ponce E, Herrero R, Munoz N, Cruz A, Shah KV, Alonso P Et al. Epidemiology of HPV infection among Mexican women with normal cytology. Int J Cancer 2001; 91: 412-20.

25. Torroelua-Kouri M, Morsberger S, CarriLO A, Mohar A, Meneses A, IbarRa M et al. HPV prevalence among Mexican women with neoplastic and normal. Gynecol Oncol 1998; 70: 115-20.

26. Ferrera A, Velema JP, Figueroa M, Bulnes R, Toro LA, Claros JM et al. Human papilloma virus infection, cervical dysplasia and invasive cancer in Honduras: a case-control study. Int J Cancer 1999; 82: 799-803.

27. Franco eL, Villa LL, Sobrinho JP, Prado JM, Rousseau MC, Desy M Et aL. Epidemiology of 
acquisition and clearance of cervical human infection in women from a high-risk area for cervical cancer. J Infect Dis 1999; 180: 1415-23.

28. Serrano ML CM, Medina O, Melgarejo D, Bravo MM. Tipificación del virus papiloma humano mediante secuencia directa en mujeres con citología normal. Revista Colombiana de Cancerología 2003; 7: 18-24.

29. van Doorn LJ, Quint W, Kleter B, Moljn A, Colau B, Martin MT ET AL. Genotyping of human papilloma virus in liquid cytology cervical by the PGMY line blot assay and the SPF(10) line probe assay. J Clin Microbiol 2002; 40: 979-83.

30. Clifford GM, Smith JS, Plummer M, Munoz N, FranCESCH S. Human papilloma virus types in invasive cervical cancer meta-analysis. Br J Cancer 2003; 88: 63-73.

31. Luaw KL, Hisng AW, Schiffman MH, You SL, Zhang T, BuRK R ET AL. Human papilloma virus types 52 and 58 are prevalent in cervical Chinese women. Int J Cancer 1997; 73: 775-6.

32. Sasagawa T, Basha W, Yamazaki $H$, Inoue M. Highrisk and multiple human papilloma virus infections cervical abnormalities in Japanese women. Cancer Epidemiol Biomarkers Prev 2001; 10: 45-52.

33. VeRNON SD, Unger ER, WiWUAMS D. Comparison of human papilloma virus detection and typing by cycle sequencing, line blotting, and hybrid capture. J Clin Microbiol 2000; 38: 651-5.

34. Ghartzadeh B, Kalantari M, García CA, Johansson B, Nyren P. Typing of human papilloma virus by pyrosequencing. Lab Invest 2001; 81: 673-9.
35. Melchers W, van den Brule A, Walboomers J, de Bruin M, Burger M, Herbrink P et al. Increased detection rate of human papilloma virus in cervical the polymerase chain reaction as compared to modified FISH and southern-blot analysis. J Med Virol 1989; 27: 329-35.

36. Ho GY, Bierman R, Beardsiey L, Chang CJ, Burk $\mathrm{RD}$. Natural history of cervicovaginal papilloma virus infection in. N Engl J Med 1998; 338: 423-8.

37. Ho GY, Burk RD, Kiein S, Kadish AS, Chang CJ, Palan P ET al. Persistent genital human papilloma virus infection as a risk persistent cervical dysplasia. J Natl Cancer Inst 1995; 87: 1365-71.

38. Bosch FX, Lorincz A, Munoz N, Mejer CJ, Shah KV. The causal relation between human papilloma virus and cervical. J Clin Pathol 2002; 55: 244-65.

39. Sotlar K, Diemer D, DethlefFs A, Hack Y, Stubner A, VOLMER N ET aL. Detection and typing of human papilloma virus by e6 nested. J Clin Microbiol 2004; 42: 3176-84.

40. Evander M, Edlund K, Boden E, Gustafsson A, JonsSON M, KaRLSSON R ET AL. Comparison of a onestep and a two-step polymerase chain degenerate general primers in a population-based study of human papilloma virus infection in young Swedish women. J Clin Microbiol 1992; 30: 987-92.

41. Husnjak K, Grce M, Magdic L, Paveuc K. Comparison of five different polymerase chain reaction methods detection of human papilloma virus in cervical cell specimens. J Virol Methods 2000; 88: 125-34. 